\title{
An optimized solar-air degree-day method to evaluate energy demand for poultry buildings in different climate zones
}

\author{
Yang WANG ${ }^{1}$, Baoming LI (ه) $)^{1,2,3}$ \\ 1 Department of Agricultural Structure and Bioenvironmental Engineering, College of Water Resources and Civil Engineering, \\ China Agricultural University, Beijing 100083, China \\ 2 Laboratory of Agricultural Engineering in Structure and Environment, Ministry of Agriculture and Rural Affairs, Beijing 100083, China \\ 3 Beijing Engineering Research Center for Animal Healthy Environment, Beijing 100083, China
}

\begin{abstract}
The degree-day method is widely used to determine energy consumption but cannot be directly applied to poultry buildings without improvements in its accuracy. This study was designed to optimize the degreeday calculation and proposes a solar-air degree-day method, which can be used to calculate the cooling and heating degree-days and the annual cooling and heating loads under different climate conditions for poultry buildings. In this paper, the solar-air degree-day method was proposed, which considers the effects of solar radiation with different wall orientations and surface colors. Five Chinese cities, Harbin, Beijing, Chongqing, Kunming and Guangzhou, were selected to represent different climate zones to determine the solar-air degreedays. The heating and cooling energy requirements for different climates were compared by DeST (Designer's Simulation Toolkit) simulation and the solar-air degreeday method. Approaches to decrease energy consumption were developed. The results showed that the maximum relative error was less than $10 \%$, and the new method was not significantly different from the DeST simulation $(P>0.05)$. The accuracy of calculating energy requirements was improved by the solar-air degree-day method in the different climate zones. Orientation and surface color effects on energy consumption need to be considered, and external walls of different orientations should have different surface colors.
\end{abstract}

Keywords base temperature, energy consumption, solar radiation, orientation, surface color

\section{Introduction}

Poultry farming is an industry growing rapidly to meet the

Received June 21, 2019; accepted August 13, 2019

Correspondence: libm@cau.edu.cn demand for eggs and meat arising from an increasing human population, and the general improvement of living standards. The indoor climate control in poultry facilities entails considerable energy consumption and the demand for energy has increased but maintaining and controlling comfortable environmental conditions is crucial to ensure poultry welfare, productivity and food safety ${ }^{[1,2]}$. In poultry buildings, energy is consumed for different purposes, such as heating and cooling systems. Usually, modern confined poultry buildings are operated with wetpad evaporative cooling, fogger and sprinkler systems in summer, and electric heaters and heat recovery systems in winter $^{[3]}$, which all require electricity. Energy is predominantly used to provide poultry production with a controlled thermal environment. During hot and cold seasons, electricity consumption drastically increases due to the use of cooling and heating equipment, thus affecting peak electricity demand in poultry buildings. Forecasting the total electricity consumption for cooling and heating require determination of the cooling and heating load profile ${ }^{[4,5]}$. Isaac and Vuuren ${ }^{[6]}$ noted that energy demand for heating and cooling purposes have risen significantly in the 21 st century, especially due to the increasing income in developing countries. Therefore, from a national energy and an environmental perspective, it has become crucial to estimate as accurately as possible the heating and cooling energy requirements in different climate zones ${ }^{[7]}$.

Most studies have determined the annual heating and cooling requirements of residential buildings by either steady-state models, computer simulation methods or degree-day methods ${ }^{[7,8]}$. In general, steady-state models allow long-term analyses of preliminary building design and scenario analyses to estimate the energy performance of buildings, without considering the inertia effect or some correction factors ${ }^{[3]}$. Yang et al. ${ }^{[9]}$ studied the effect of different building envelopes for different climate zones in China utilizing the overall thermal transfer value approach, while Mattia et al. ${ }^{[8]}$ observed that the main limitation of 
this approach was the fact that the inertia of the building envelop was not included. In contrast, dynamic simulation of buildings by computer methods, such as DeST (Designer's Simulation Toolkit), DOE-2, Energy Plus and TRNSYS, are becoming more accurate, and are becoming powerful tools for construction professionals to develop highly energy-efficient building designs. In fact, simplified building energy estimation models permit the evaluation of heating/cooling loads with a satisfactory level of accuracy at moderate computational $\operatorname{cost}^{[10,11]}$. The degree-day method is still essential to analyze building energy consumption. It represents a very simple and costeffective method to estimate building annual cooling and heating loads by performing very simple and fast calculations. The calculations are based on the fact that the heating and cooling loads are proportional to the difference between ambient air temperature and internal reference or base temperature. The base temperature is the indoor air temperature below which a building requires heating and above which a building requires cooling to maintain the desired thermal environmental conditions.

Although previous studies have acknowledged that the degree-day method is a common, simple and widespread method used to assist in estimating of energy consumption $^{[12-15]}$, cooling and heating energy consumption calculated by this method are not sufficiently reliable or consistent for poultry buildings. The reasons for this are, firstly, heat losses in poultry buildings generally occur through building components (external walls, ceilings, floors and doors) and ventilation systems. Solar radiation is largely neglected in the degree-day method when calculating the cooling and heating degree-days, even though solar radiation heat is absorbed by large external surfaces and will be transmitted into the inner surfaces by conduction. Convection thermal transmissions occur between outdoor air and the outer surface of walls, and between the inner surface and indoor air ${ }^{[12,13]}$. Yu et al. ${ }^{[12]}$ considered the solar radiation in the degree method to calculate solar-air degree-days in hot summer and cold winter zone of China. However, the solar-air degree-day method has not been verified, and the adaptability of different climate zones has not been adequately studied. Solar radiation should be taken into consideration because the area of the surfaces of poultry building is larger than for residential buildings. Meanwhile, the structure of the external envelopes is different from residential buildings, and the parameters of degree-days for residential buildings cannot be directly used in poultry buildings. Civil buildings are dominated by brick and concrete structures, but about $95 \%$ of poultry buildings have sandwich structures (color steel laminboard) in rebuilt and new buildings ${ }^{[3]}$. Secondly, although the heat transfer of external envelopes is orientation dependent, heat transfer through the opaque envelopes calculated with the degree-day method does not take account of envelope orientations and surface color, hence, orientations and surfaces color need to be considered.
Finally, the accuracy of the degree-day method for estimating cooling and heating energy consumption partly depends on the degree days. Livestock buildings usually adopt the standards of residential buildings cooling and heating degree days. The base temperature is $26^{\circ} \mathrm{C}$ for cooling and $18^{\circ} \mathrm{C}$ for heating in residential buildings, but different animals have different calculation parameters. An appropriate base temperature for different animals helps to obtain a realistic representation of building energy consumption, whereas an inappropriate one may give misleading results ${ }^{[11]}$. Therefore, a more relevant definition and appropriate values of degree-days is required for poultry buildings.

This paper aims at optimizing the cooling and heating degree-day method in the building energy estimation, which can be used to calculate the cooling and heating degree-days, and the annual cooling and heating loads in all climate conditions of poultry buildings.

\section{Materials and methods}

\subsection{Solar-air cooling and heating degree-day method}

The cooling and heating degree-day method is the simplest and most efficient way to calculate the envelope heat transfer, which assumes that the energy requirement is proportional to the difference between outdoor temperature and indoor base temperature ${ }^{[12,14,15]}$. However, solar-air degree-day calculations are obtained by replacing the ambient temperature with the solar-air temperature and replacing the indoor design temperature with the relevant indoor base temperature the animals require and are mathematically similar to the concepts developed by $\mathrm{Yu}$ et al. ${ }^{[12,14]}$. The solar-air temperature refers to the temperature under the action of outdoor temperature, solar radiation and atmospheric long-wave radiation ${ }^{[16,17]}$. The solar-air degree-day method for poultry buildings calculates the annual cooling and heating energy consumption in a given building under conditions of variable meteorological parameters.

\subsubsection{Solar-air cooling degree-days and heating degree-days}

Considering both outside air temperature and solar radiation, solar-air degree-days for poultry buildings are proposed to estimate energy consumption. Limiting the whole year to cooling and heating seasons on the basis of the calculation of existing degree-days ${ }^{[18]}$, which includes solar-air heating degree-days (SHDD*) and solar-air cooling degree-days (SCDD*). The total SHDD* and SCDD* can be calculated with Eq. (1) and Eq. (2).

$$
\mathrm{SCDD}^{*}=\sum_{1}^{365}\left(t_{s}-t_{i}\right) \text { for } t_{s} \gg t_{i}
$$




$$
\mathrm{SHDD}^{*}=\sum_{1}^{365}\left(t_{i}-t_{s}\right) \text { for } t_{s} \ll t_{i}
$$

Where SCDD* is the solar-air cooling and heating degreedays, ${ }^{\circ} \mathrm{C} \cdot \mathrm{d}$; SHDD* is the solar-air heating degree-days, ${ }^{\circ} \mathrm{C} \cdot \mathrm{d}$; $t_{i}$ is the base temperature, and is different for cooling and heating degree-days, ${ }^{\circ} \mathrm{C}$; and $t_{s}$ is the solar-air temperature, ${ }^{\circ} \mathrm{C}$, which takes solar radiation absorptance into account, and is determined by outside air temperature, solar radiation absorptance and daily average solar total radiation of the envelope surface. The solar-air temperature is determined with Eq. (3).

$$
\begin{gathered}
t_{s}=t_{o}+\Delta t \\
\Delta t=\frac{\rho J_{t}}{\alpha_{o}}-3.5 \text { for horizontal surface } \\
\Delta t=\frac{\rho J_{t}}{\alpha_{o}} \text { for vertical surface }
\end{gathered}
$$

Where $t_{o}$ is the outside air temperature, ${ }^{\circ} \mathrm{C} ; \Delta t$ is the temperature difference between the solar-air temperature and the outside air temperature, ${ }^{\circ} \mathrm{C}$, and the temperature difference between the solar-air temperature and the outside air temperature is determined by Eq. (4) and Eq. $(5)^{[19]}$; and $\rho$ is the solar radiation absorptance, which represents the ratio of the solar radiation illuminance absorbed by the outer surface of the envelope exposed to the solar radiation illuminance. The envelope outer surface color has a significant influence on the solar radiation absorbed in different climate zones. The sandwich structure was used in the calculations for the cities analyzed $^{[3]}$. The sandwich wall consists of rigid foam insulation between inside and outside layers. The structure of color steel laminboard consists of $0.2 \mathrm{~mm}$ smooth external steel layer (light, mid and deep colored surface), insulation material, and $0.2 \mathrm{~mm}$ inner steel layer. The data for solar radiation absorptance are present in various buildings design codes, data from Code for Design of Civil Buildings ${ }^{[13]}$ were used and reported that the light, mid and deep color solar radiation absorptance of new materials are $0.25,0.50$ and 0.75 , respectively; $J_{t}$ is the daily average total solar radiation, in $\mathrm{W} \cdot \mathrm{m}^{-2}$, and the daily averaged total solar radiation is according to the design code for heating ventilation and air conditioning of civil buildings (GB 50736-2012) ${ }^{[16]} ; \alpha_{o}$ is the external surface coefficient of heat transfer, in $\mathrm{W} \cdot \mathrm{m}^{-2} \cdot \mathrm{K}^{-1}$, considering the surface characteristics of the envelopes of the poultry house, and the external surface coefficient of heat transfer was assigned a value of $23 \mathrm{~W} \cdot \mathrm{m}^{-2} \cdot \mathrm{K}^{-1[19]}$.

2.1.2 Annual cooling and heating energy consumption of building external envelopes

The heat losses in livestock buildings generally occur through building components (external walls, ceilings, floors and doors) and through ventilation systems. Heat loss through ventilation, which varies depending on the capacity of the laying houses, was not considered in the degree-day method study. In the current study, the energy consumption for poultry buildings was calculated by considering heat losses from the building's external envelope. The solar radiation heat absorbed by the large external surfaces of livestock buildings is transmitted to the inner surfaces by conduction. Meanwhile, convection thermal transmission occurs between outside air and the outer surface of walls, and between the inner surface and indoor air ${ }^{[17]}$. Heat loss through a unit area of external wall was calculated by Eq. (6).

$$
q_{w}=U\left(t_{i}-t_{s a}\right)
$$

Where $q_{w}$ is the heat loss per unit area of wall, $\mathrm{W} \cdot \mathrm{m}^{-2} ; U$ is the heat transfer coefficient of external wall, and assumed to be constant, $\mathrm{W} \cdot \mathrm{m}^{-2} \cdot \mathrm{K}^{-1}$. In this study, calculations were only performed for electricity as the energy source, the annual heat loss per unit area of external wall $q_{w}$ can be determined using the solar-air degree days and $U$ value, and is given by Eq. (7).

$$
Q_{h}=86400 \times U \times \text { SHDD }^{*}
$$

Where $Q_{h}$ is the annual heat loss per unit area, $\mathrm{MJ} \cdot \mathrm{m}^{-2}$; and 86400 is the unit conversion coefficient.

For a useful approximation, heating and cooling energy requirements can be assumed to be proportional to the SHDD* and SCDD*, respectively. The annual energy requirement can be determined by dividing the annual heat loss by the efficiency of the heating system $\eta_{h}$, and the annual energy consumption for heating per unit area of external wall is expressed by Eq. (8).

$$
E_{h}=\frac{U \times \text { SHDD }^{*} \times 24}{1000 \times \eta_{h}}
$$

Where $E_{h}$ is the annual energy consumption for heating per unit area, $\mathrm{kW} \cdot \mathrm{h} \cdot \mathrm{m}^{-2}$; and $\eta_{h}$ is the efficiency of the heating system, and $\eta_{h}$ is $1.9^{[13]}$.

Similarly, the annual cold loss per unit area of external wall is expressed by Eq. (9).

$$
Q_{c}=86400 \times U \times \mathrm{SCDD}^{*}
$$

Where $Q_{c}$ is the annual cold loss per unit area, $\mathrm{MJ} \cdot \mathrm{m}^{-2}$. The annual energy consumption for cooling per unit area of external wall is expressed by Eq. (10).

$$
E_{c}=\frac{U \times \mathrm{SCDD}^{*} \times 24}{1000 \times \eta_{c}}
$$

Where $E_{c}$ is the annual energy consumption for cooling per unit area, $\mathrm{kW} \cdot \mathrm{h} \cdot \mathrm{m}^{-2}$; and $\eta_{c}$ is the energy efficiency ratio of the cooling system. The energy type for poultry farming depends on energy policy, native resources advantage and 
farm investment, while the cooling and heating system, local climate characteristic and thermal climate condition requirements have a significant influence on the energy efficiency ratio of the cooling and heating system used in poultry farming. The parameters of the energy efficiency ratio for the cooling and heating system in the different climate zones used for the annual energy consumption calculations in Table 1 come from Code for Design of Civil Buildings ${ }^{[13]}$.

\subsection{Meteorological data}

The results for the solar-air degree-days and building energy consumption based on climate data from different years are quite different, due to stochastic variation in the weather ${ }^{[18,19]}$. To improve accuracy of solar-air degreedays and building energy consumption results, a weather file (including temperature, relative humidity, radiation, air speed and precipitation) is needed, along with the information on the ambient conditions on an hourly basis for the whole year. The weather file includes the parameters of the dry bulb air temperature, the maximum and minimum air temperature, the relative humidity of the air, and the daily average solar radiation. These weather files should be for a typical year extracted from historical data (most often over 15-30 years) due to stochastic variation as reported by Bhatnagar et al. ${ }^{[7]}$. Additionally, it is necessary to select typical climate data of one year from long-term data based on the simulation purpose. Meteorological data of a typical year for the five cities included in the study were provided by Medpha (Tsinghua University, Beijing, China), based on observation data from the past 30 years, as per the Climatic Data Centre of the China Meteorological Administration and Tsinghua University $^{[20-22]}$. Thus, these data were used to determine the solar-air cooling and heating degree-days and annual cooling and heating energy consumptions in poultry buildings in this study.

\subsection{Model validation}

This part compared the calculated and simulated results to verify the reliability of the solar-air degree-day method in a model validation test performed in a real laying house. In this paper, the DeST developed by Tsinghua University since the late 1980s was adopted. Compared with the widely-used simulation tool (computational fluid dynamics, CFD), DeST can simulate housing environments under diabatic conditions, which is more realistic and useful for farm managements ${ }^{[20]}$. All simulation stages in DeST were performed on a graphical user interface developed by AutoCAD, which supported the input (including materials, geometric dimensions and internal gains) and output information. All model parameters were used to establish the topological structure of the building, which could simulate real scenarios of the building's energy consumption, and the results were given in Microsoft Excel format for easy reference ${ }^{[21,22]}$. In DeST simulation, the poultry building construction was considered as tightness ${ }^{[3]}$. The DeST simulation results were accurate and convincing, as demonstrated by an energy demand evaluation experiment conducted before modeling. Also, it assumed the heat transfer coefficient of the external envelope to be constant, and the total heat production to be determined as a function of weight ${ }^{[1]}$.

\subsubsection{Housing, animals and management}

A commercial poultry building containing 30000 hens was considered in this study. The east-west orientated laying house was $96 \mathrm{~m} \times 12 \mathrm{~m} \times 3.6 \mathrm{~m}$ (length $\times$ width $\times$ height) and the heights of sidewalls and rooftop were $3.6 \mathrm{~m}$ and $4.8 \mathrm{~m}$, respectively. The value for heat production by hens under optimum internal production temperature conditions were calculated using the methods of Olgun et al. ${ }^{[18]}$. The sensible, latent, and total heat production were 9.18, 3.96 and $13.1 \mathrm{~W}$ per hen, respectively. In the laying house, the best indoor climate conditions for the layers depend on the hen's age, and ideal climate condition data are present in various layer management guides and literature ${ }^{[1,3,17,18]}$. For the development of the presented solar-air degree-day method, the base temperature is either the lower or higher limit of the optimum internal production temperature range of the animals, $24^{\circ} \mathrm{C}$ for cooling and $18^{\circ} \mathrm{C}$ for heating, and data from Kocaman et al. ${ }^{[17]}$ were used as shown in Table 2. All the geometric characteristics of the building are listed in Table $3^{[16,19]}$. This commercial poultry building is a sandwich envelope structure (color steel

Table 1 Parameters of the energy efficiency ratio for the cooling and heating system

\begin{tabular}{lccccc}
\hline Type & Severe cold & Cold & Hot summer and cold winter & Temperate & Hot summer and warm winter \\
\hline$\eta_{c}$ & 2.65 & 2.70 & 2.75 & 2.65 & 2.75 \\
$\eta_{h}$ & 3.25 & 3.35 & 3.40 & 3.30 & 3.45 \\
\hline
\end{tabular}

Table 2 Optimum production temperature and base temperature for poultry ${ }^{[17]}$

\begin{tabular}{lccc}
\hline Animals & Optimum temperature $/{ }^{\circ} \mathrm{C}$ & Base temperature for cooling $/{ }^{\circ} \mathrm{C}$ & Base temperature for heating $/{ }^{\circ} \mathrm{C}$ \\
\hline Laying hens $(127-432 \mathrm{~d})$ & $18-24$ & 24 & 18 \\
\hline
\end{tabular}


Table 3 Geometric and structure characteristics of the building considered ${ }^{[16,19]}$

\begin{tabular}{lccc}
\hline Building envelope & Area $/ \mathrm{m}^{2}$ & Building envelope components & Heat transfer coefficient $/\left(\mathrm{W} \cdot \mathrm{m}^{-2} \cdot \mathrm{K}^{-1}\right)$ \\
\hline Roof & 1173 & $200 \mathrm{~mm}$ polyurethane foam & 0.29 \\
Wall & 752 & $150 \mathrm{~mm}$ polyurethane foam & 0.39 \\
Door & 4.0 & single-deck wooden & 4.76 \\
Window & 11.5 & polystyrene of the metal frame & 6.67 \\
Fan & 24.0 & galvanized and stainless steel & 10.0 \\
Floor & 1152 & concrete & 0.47 \\
\hline
\end{tabular}

Note: Specific heat of foamed polyurethane is $0.36 \mathrm{~J} \cdot \mathrm{kg}^{-1} \cdot \mathrm{K}^{-1}$, heat storage is $50 \mathrm{~W} \cdot \mathrm{m}^{-2} \cdot \mathrm{K}^{-1}$.

laminboard). Color steel laminboard consists of $0.2 \mathrm{~mm}$ mid-colored external steel layer, insulation material, and $0.2 \mathrm{~mm}$ inner steel layer. The building envelope openings and leaks were tightly sealed, as demonstrated by a pressure difference evaluation experiment conducted before modeling.

\subsubsection{Climate zones information}

Five cities were selected to represent the major climate types in China: Harbin (45.75' N, 126.76' E, severe cold), Beijing (39.80' N, 116.46' E, cold), Chongqing (29.58' N, $106.46^{\prime} \mathrm{E}$, hot summer-cold winter), Kunming (25.01' N, $102.68^{\prime} \mathrm{E}$, temperate) and Guangzhou $\left(23.16^{\prime} \mathrm{N}\right.$, $113.33^{\prime} \mathrm{E}$, hot summer-warm winter). Data from these cities were used to determine solar-air degree-days for each climate zone. Thus, results reported herein for the selected cities may be conveniently used to obtain reasonable estimates of solar-air degree-days for other cities within the different climate zones ${ }^{[15]}$, thereby improving the accuracy of the degree-day method by using the appropriate base temperature and solar-air degree-days in a given climate zone.

\subsection{Statistical analysis}

Data obtained from the calculation and simulation were analyzed by Origin 9.0 (Origin Laboratory, Northampton,
MA, USA). The absolute and relative errors were used to evaluate the difference between the calculated value and simulated value, and the absolute $(\Delta E)$ and relative $\left(\Delta \delta_{E}\right)$ errors were determined using Eq. (11) and Eq. (12).

$$
\begin{gathered}
\Delta E=E_{C A}-E_{S I} \\
\Delta \delta_{E}=\frac{\left|E_{C A}-E_{S I}\right|}{E_{S I}}
\end{gathered}
$$

Where $E_{C A}$ is the calculated annual energy consumption determined by the degree-day method, $\mathrm{kW} \cdot \mathrm{h} \cdot \mathrm{m}^{-2} ; E_{S I}$ is the simulated annual energy consumption by DeST, $\mathrm{kW} \cdot \mathrm{h} \cdot \mathrm{m}^{-2} ; \Delta E$ is the absolute error, $\mathrm{kW} \cdot \mathrm{h} \cdot \mathrm{m}^{-2} ;$ and $\Delta \delta_{E}$ is the relative error, $\%$.

\section{Results}

\subsection{Comparisons of calculation and simulation results}

To extend the capabilities of model testing for different types of climatic conditions, several calculations and simulations were performed using the solar-air cooling and heating degree-day method and DeST simulation. The heating and cooling solar-air degree-days in a laying house at a base temperature of $24^{\circ} \mathrm{C}$ for cooling and $18^{\circ} \mathrm{C}$ for heating is shown in Table 4. The annual cooling and heating demand for the commercial laying house

\begin{tabular}{|c|c|c|c|c|c|c|c|}
\hline City & Degree-days $/\left({ }^{\circ} \mathrm{C} \cdot \mathrm{d}\right)$ & $S$ & SE/SW & $\mathrm{E} / \mathrm{W}$ & $\mathrm{NE} / \mathrm{NW}$ & $\mathrm{N}$ & $\mathrm{H}$ \\
\hline \multirow[t]{2}{*}{ Harbin } & SCDD* & 198 & 249 & 245 & 164 & 99 & 290 \\
\hline & SHDD* & 4404 & 4230 & 4242 & 4544 & 4868 & 4109 \\
\hline \multirow[t]{2}{*}{ Beijing } & SCDD* & 516 & 629 & 658 & 524 & 382 & 759 \\
\hline & SHDD* & 2084 & 1898 & 1855 & 2069 & 2340 & 1994 \\
\hline \multirow[t]{2}{*}{ Chongqing } & SCDD* & 666 & 886 & 1014 & 877 & 650 & 1194 \\
\hline & SHDD* & 722 & 529 & 437 & 536 & 738 & 328 \\
\hline \multirow[t]{2}{*}{ Kunming } & SCDD* & 2 & 44 & 119 & 65 & 8 & 226 \\
\hline & SHDD* & 862 & 632 & 507 & 581 & 783 & 393 \\
\hline \multirow[t]{2}{*}{ Guangzhou } & SCDD* & 912 & 1248 & 1530 & 1433 & 1151 & 1770 \\
\hline & SHDD* & 236 & 131 & 74 & 91 & 157 & 42 \\
\hline
\end{tabular}

Table 4 SHDD* and SCDD* in laying house $\left({ }^{\circ} \mathrm{C} \cdot \mathrm{d}\right.$ ) at a base temperature of $24^{\circ} \mathrm{C}$ (cooling) and $18^{\circ} \mathrm{C}$ (heating)

Note: S, south; SE, south-east; SW, south-west; E, east; W, west; NE, north-east; NW, north-west; N, north; H, horizontal. 
configurations were compared as shown in Fig. 1. The comparisons showed that the solar-air degree-day method calculations and simulations predicted similar cooling and heating energy demand for the different climate conditions. Table 5 shows the absolute and relative errors compared with DeST simulation based on the five cities. The absolute error and relative errors of the solar-air degree-day method were reduced compared with degree-day method. The absolute error of cooling energy demand was reduced from 0.55 to $0.08 \mathrm{~kW} \cdot \mathrm{h} \cdot \mathrm{m}^{-2}$ in Harbin, from 0.45 to $0.05 \mathrm{~kW} \cdot \mathrm{h} \cdot \mathrm{m}^{-2}$ in Beijing, from 0.90 to $0.04 \mathrm{~kW} \cdot \mathrm{h} \cdot \mathrm{m}^{-2}$ in Chongqing, from 0.18 to $0.06 \mathrm{~kW} \cdot \mathrm{h} \cdot \mathrm{m}^{-2}$ in Kunming, and from 1.40 to $0.26 \mathrm{~kW} \cdot \mathrm{h} \cdot \mathrm{m}^{-2}$ in Guangzhou. The relative error of heating energy demand was reduced from $10.8 \%$ to $1.12 \%$ in Harbin, from $17.9 \%$ to $7.85 \%$ in Beijing, from $18.6 \%$ to $1.46 \%$ in Chongqing, from $15.7 \%$ to $5.86 \%$ in Kunming, and from $33.0 \%$ to $9.23 \%$ in Guangzhou. There was no significant difference in cooling and heating energy demand between the results from the solar-air degree-day method and DeST simulation $(P>0.05)$, but the cooling and heating energy demand between solar-air degree-day method and degree-day method were statistically different $(P<0.05)$, and the cooling and heating energy demand between the results from the degree-day method and DeST were statistically different $(P<0.05)$.

\subsection{Solar-air cooling and heating degree-days}

Figure 2 shows the effect of wall orientations and external surfaces color on temperature difference between the solarair temperature and the outside air temperature in the five climate zones. It can be seen that the maximum temperature difference between the solar-air temperature and the outside air temperature occurs for the east-west orientated walls with a light colored surface, and horizontal orientations with mid and deep colored surfaces.
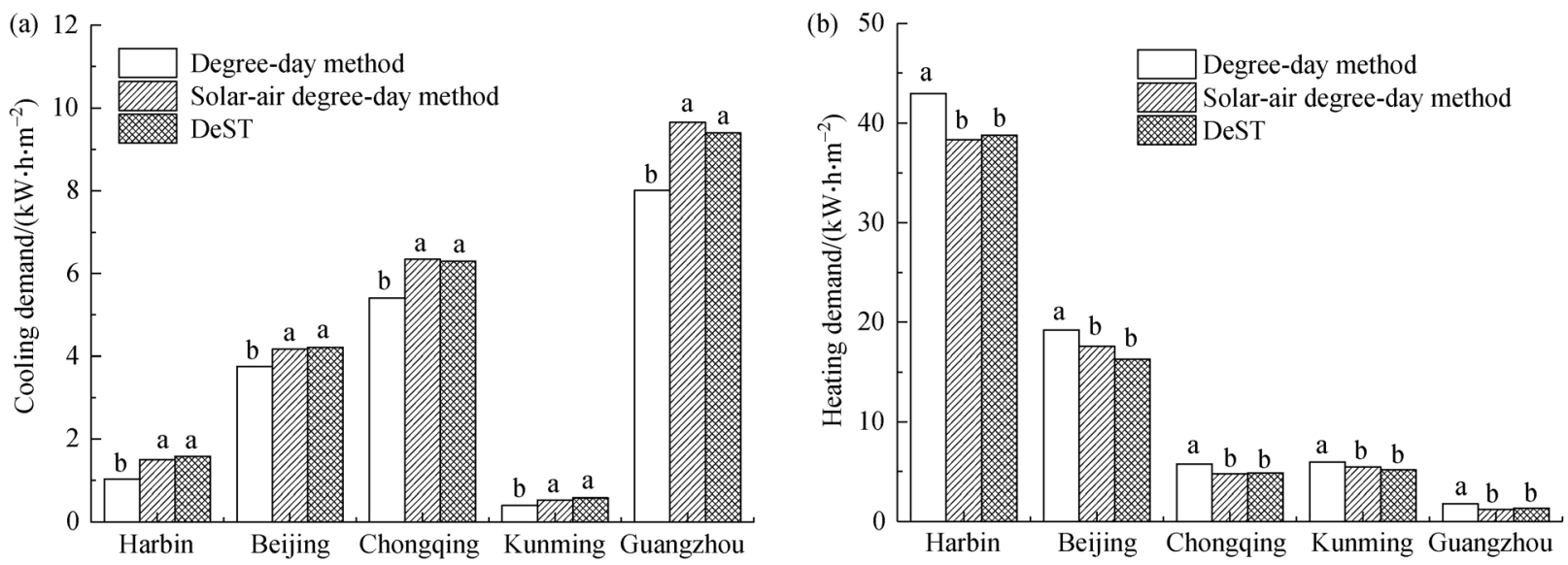

Fig. 1 Comparison of cooling (a) and heating (b) energy demand calculated by the degree-day method, solar-air degree-day method and DeST simulation for five cities in different climate zones of China. Within a city, bars with the same letters are not significantly different $(P<0.05)$.

Table 5 Absolute $(\Delta E)$ and relative $\left(\Delta \delta_{E}\right)$ errors compared with DeST simulation based on five cities in different climate zones of China

\begin{tabular}{|c|c|c|c|c|c|}
\hline \multirow{2}{*}{ Period } & \multirow{2}{*}{ City } & \multicolumn{2}{|c|}{ Degree-day method } & \multicolumn{2}{|c|}{ Solar-air degree-day method } \\
\hline & & $\mathrm{kW} \cdot \mathrm{h} \cdot \mathrm{m}^{-2}$ & $\%$ & $\mathrm{~kW} \cdot \mathrm{h} \cdot \mathrm{m}^{-2}$ & $\%$ \\
\hline \multirow[t]{5}{*}{ Cooling demand } & Harbin & 0.55 & 34.8 & -0.08 & 5.22 \\
\hline & Beijing & 0.45 & 10.7 & -0.05 & 1.15 \\
\hline & Chongqing & 0.90 & 14.3 & 0.04 & 0.69 \\
\hline & Kunming & 0.18 & 31.0 & -0.06 & 9.59 \\
\hline & Guangzhou & 1.40 & 14.9 & 0.26 & 2.71 \\
\hline \multirow[t]{5}{*}{ Heating demand } & Harbin & -4.20 & 10.8 & -0.43 & 1.12 \\
\hline & Beijing & -2.91 & 17.9 & 1.28 & 7.85 \\
\hline & Chongqing & -0.90 & 18.6 & -0.07 & 1.46 \\
\hline & Kunming & -0.81 & 15.7 & 0.30 & 5.86 \\
\hline & Guangzhou & -0.44 & 33.0 & -0.13 & 9.63 \\
\hline
\end{tabular}



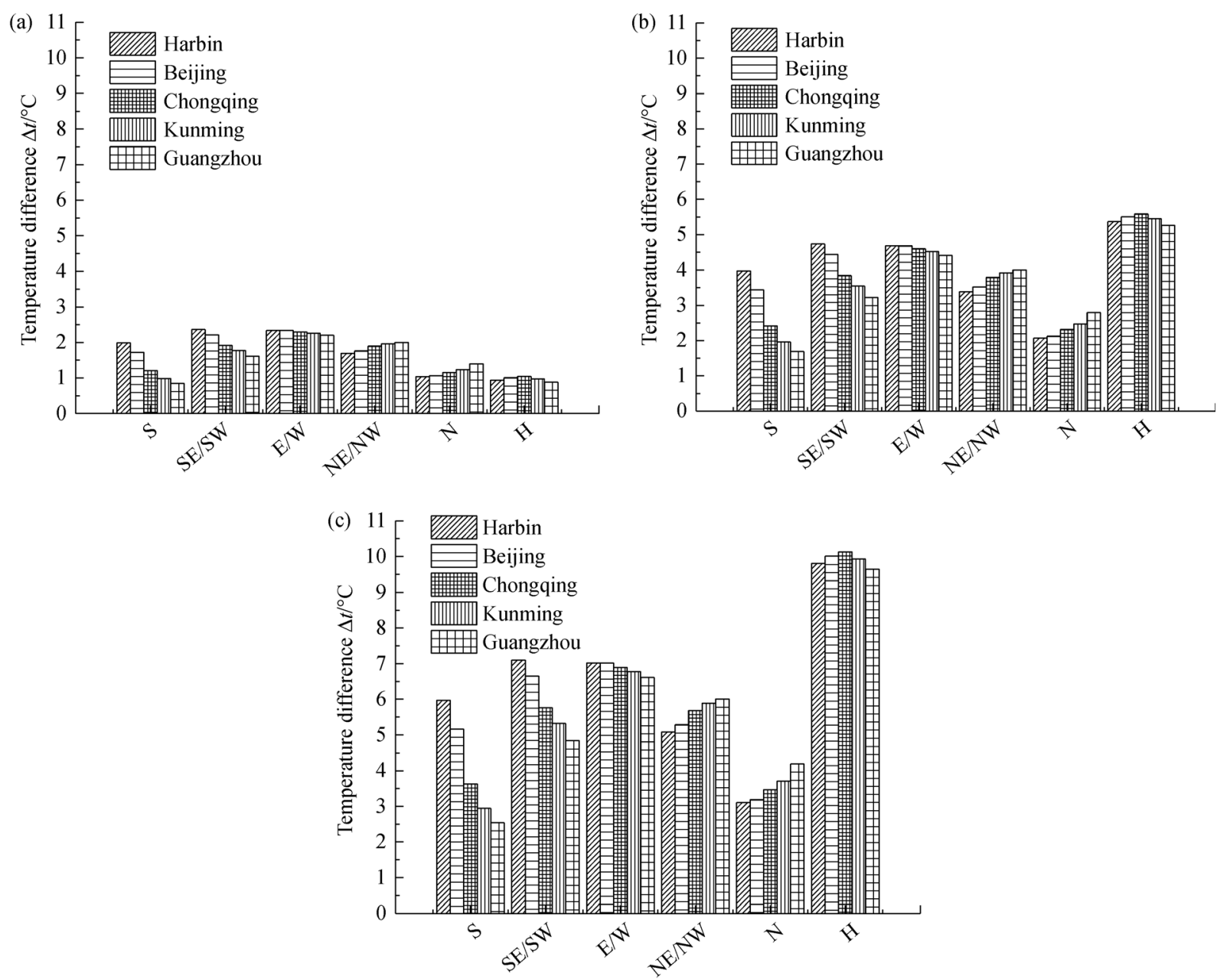

Fig. 2 Effect of external surface color and orientation on temperature difference between the solar-air temperature and the outside air temperature in five cities in different climate zones of China. (a) Light color; (b) mid color; (c) deep color. S, south; SE, south-east; SW, south-west; E, east; W, west; NE, north-east; NW, north-west; N, north; H, horizontal.

Additionally, the deeper the color of the surface, the higher the temperature difference. The surface color had a great effect on solar-air temperature. For example, for Beijing with a deep colored surface, values of temperature difference between the solar-air temperature and the outside air temperature of south, south-east-south-west, east-west, north-east-north-west, north, and horizontal orientations were $5.16,6.65,7.01,5.28,3.19$, and $9.93^{\circ} \mathrm{C}$, respectively.

Figure 3 shows the variation in solar-air cooling and heating degree-days for a light colored external surface in different climate zones, with various base temperatures. Clearly, an increase in base temperature in the five cities reduced the solar-air cooling degree-days in a linear fashion. Increasing the base temperature from 21 to $25^{\circ} \mathrm{C}$ resulted in about $56 \%$ lower solar-air cooling degree-days in Harbin, and 45\% in Beijing, $42 \%$ in Chongqing, $73 \%$ in Kunming, and $40 \%$ in Guangzhou. Notably, solar-air heating degree-days increased almost linearly with increasing base temperature. There is no need for heating in Guangzhou poultry buildings when the base temperature is less than $16^{\circ} \mathrm{C}$, in hot summer and warm winter zones, for which the value of the heating degree-day is zero. Decreasing base temperature from the value of 18 to $15^{\circ} \mathrm{C}$ resulted in about $16 \%$ lower heating degree-days in Harbin, and decreases of $29 \%$ in Beijing, $68 \%$ in Chongqing, $61 \%$ in Kunming, and $85 \%$ in Guangzhou.

The solar-air heating and cooling degree-days for laying hens in each of the cities was calculated with Eq. (1) and Eq. (2) using solar-air temperature values and at the corresponding lower and higher limits of the optimum internal production temperature as base temperature, depending on the temperature data of the cities selected (Table 6). The cold region in China was represented by Beijing with an average SHDD* of $2432^{\circ} \mathrm{C} \cdot \mathrm{d}$ and SCDD* of $340^{\circ} \mathrm{C} \cdot \mathrm{d}$, whereas Harbin, in a severe cold zone, showed an average SHDD* of $4961^{\circ} \mathrm{C} \cdot \mathrm{d}$ and SCDD* of $86^{\circ} \mathrm{C} \cdot \mathrm{d}$ with light colored external surface laying house. According to these values, energy consumption in Harbin would be twice that in Beijing for a base temperature of 

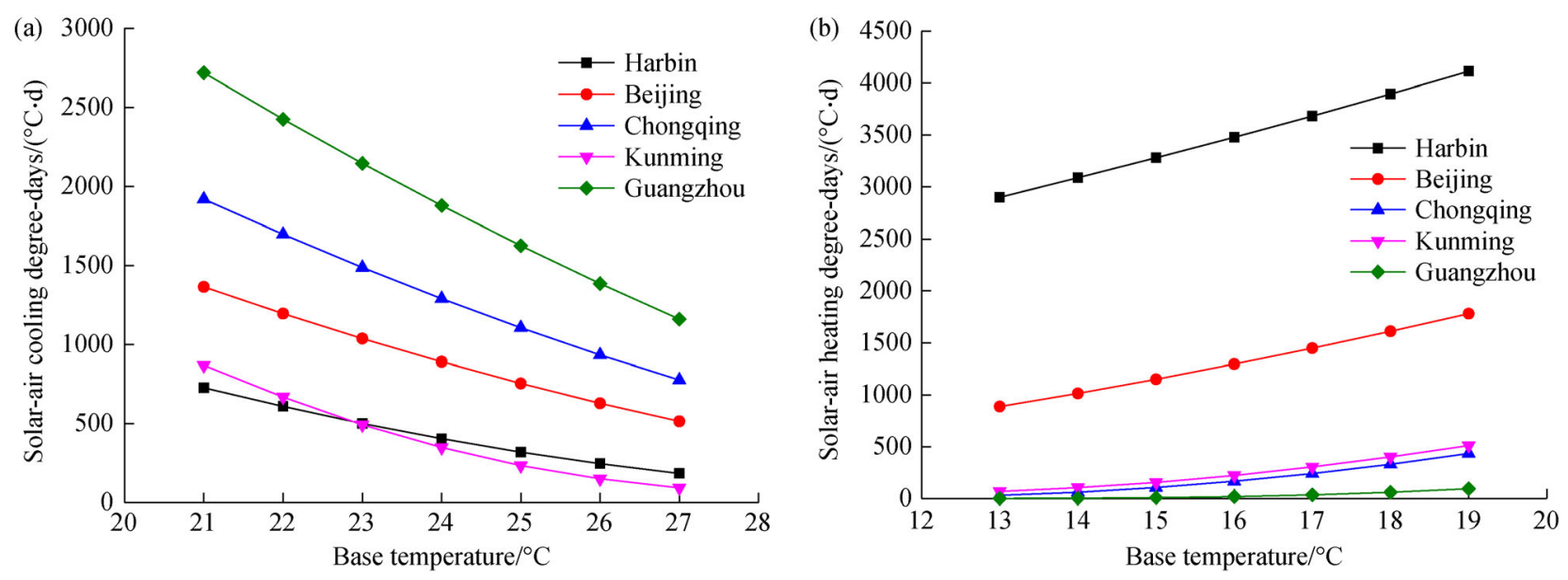

Fig. 3 Effect of base temperatures on solar-air cooling (a) and heating (b) degree-days for five cities in different climate zones of China.

$18^{\circ} \mathrm{C}$ in the heating period, while energy consumption in Beijing would be nearly four times greater than in Harbin for a base temperature of $24^{\circ} \mathrm{C}$ in the cooling period, under the same building conditions. The highest solar-air heating degree-day value was found in Harbin (SHDD $*=5179$, light colored surface), located in the severe cold region, and the lowest solar-air heating degree-day value was found in Kunming (SCDD* $=0$, light color) in the temperate zone. The SHDD* value was calculated as zero for a deep colored surface in Guangzhou and the conclusions regarding solar-air cooling degree-days were the opposite.

Solar-air cooling degree-day values for different orientations were clearly different in Guangzhou and Chongqing. The maximum difference in average solar-air cooling degree-day value between south orientated and horizontal orientation with the same surface color in Guangzhou was higher than $1940^{\circ} \mathrm{C} \cdot \mathrm{d}$ and in Chongqing it was higher than $1320^{\circ} \mathrm{C} \cdot \mathrm{d}$. In Guangzhou, the deeper the surface color, the higher the solar-air cooling degree-days. When the surface color was changed from deep to light, the maximum difference of average solar-air cooling degree-day value reached $1003^{\circ} \mathrm{C} \cdot \mathrm{d}$. Table 5 shows that the cooling energy needed in severe cold, cold and temperate zones are rather lower than the requirements for hot summer-cold winter and hot summer-warm winter zones ${ }^{[23]}$.

\subsection{Cooling and heating energy consumption}

Figure 4 shows the cooling and heating energy demand for six orientations of deep colored surface in the five cities. The cooling energy demand for six orientations ranged from 1.07 to $5.39 \mathrm{~kW} \cdot \mathrm{h} \cdot \mathrm{m}^{-2}$ in Harbin, from 3.52 to $10.6 \mathrm{~kW} \cdot \mathrm{h} \cdot \mathrm{m}^{-2}$ in Beijing, from 5.94 to $15.6 \mathrm{~kW} \cdot \mathrm{h} \cdot \mathrm{m}^{-2}$ in Chongqing, from 0.14 to $7.96 \mathrm{~kW} \cdot \mathrm{h} \cdot \mathrm{m}^{-2}$ in Kunming, and from 7.87 to $21.8 \mathrm{~kW} \cdot \mathrm{h} \cdot \mathrm{m}^{-2}$ in Guangzhou. The horizontal direction had a great effect on cooling energy consumption, but a relatively smaller effect on heating energy consumption. Solar-air cooling degree-day values for different orientations were clearly different in Guangzhou and Chongqing, so was the difference in average cooling energy demand. The maximum difference in cooling energy demand between south orientated and horizontal orientation, with the deep surface color in Guangzhou was higher than $14.0 \mathrm{~kW} \cdot \mathrm{h} \cdot \mathrm{m}^{-2}$ and in Chongqing it was higher than $7.82 \mathrm{~kW} \cdot \mathrm{h} \cdot \mathrm{m}^{-2}$.

The cooling and heating energy demand for different colored surfaces in the five cities are shown in Fig. 5. The heating energy demand for different colored surfaces ranged from 34.0 to $43.2 \mathrm{~kW} \cdot \mathrm{h} \cdot \mathrm{m}^{-2}$ in Harbin, from 14.0 to $21.1 \mathrm{~kW} \cdot \mathrm{h} \cdot \mathrm{m}^{-2}$ in Beijing, from 2.88 to $7.39 \mathrm{~kW} \cdot \mathrm{h} \cdot \mathrm{m}^{-2}$ in Chongqing, from 3.51 to $8.16 \mathrm{~kW} \cdot \mathrm{h} \cdot \mathrm{m}^{-2}$ in Kunming, and from 0.52 to $2.21 \mathrm{~kW} \cdot \mathrm{h} \cdot \mathrm{m}^{-2}$ in Guangzhou. In Guangzhou, the deeper the surface color, the higher the cooling energy demand. The maximum difference in average cooling energy demand was $7.22 \mathrm{~kW} \cdot \mathrm{h} \cdot \mathrm{m}^{-2}$ when changing the surface color from deep to light in Guangzhou. In contrast, the deeper the surface color, the lower the heating energy demand, particularly in Harbin. The maximum difference of average heating energy demand reached $9.29 \mathrm{~kW} \cdot \mathrm{h} \cdot \mathrm{m}^{-2}$.

\section{Discussion}

\subsection{The absolute error and relative error}

The accuracy of estimating the cooling and heating energy demand was improved by the solar-air degree-day method. The maximum absolute error in cooling and heating energy demand was reduced from 1.40 to $0.26 \mathrm{~kW} \cdot \mathrm{h} \cdot \mathrm{m}^{-2}$, and from 4.20 to $1.28 \mathrm{~kW} \cdot \mathrm{h} \cdot \mathrm{m}^{-2}$, respectively. The maximum relative errors of cooling and heating energy demand were less than $10 \%$ with the solar-air degree-day method. Further, the heating and cooling energy demand for different climates calculated with the solar-air degree-day 
Table 6 SHDD* and SCDD* in laying house at a base temperature of $24^{\circ} \mathrm{C}$ (cooling) and $18^{\circ} \mathrm{C}$ (heating)

\begin{tabular}{|c|c|c|c|c|c|c|c|c|}
\hline City & Degree-days $/\left({ }^{\circ} \mathrm{C} \cdot \mathrm{d}\right)$ & External surface color & $\mathrm{S}$ & $\mathrm{SE} / \mathrm{SW}$ & $\mathrm{E} / \mathrm{W}$ & $\mathrm{NE} / \mathrm{NW}$ & $\mathrm{N}$ & $\mathrm{H}$ \\
\hline \multirow[t]{6}{*}{ Harbin } & SCDD* & Light & 95 & 112 & 111 & 83 & 61 & 56 \\
\hline & & Mid & 198 & 249 & 245 & 164 & 99 & 290 \\
\hline & & Deep & 349 & 457 & 449 & 276 & 149 & 748 \\
\hline & SHDD* & Light & 4889 & 4794 & 4800 & 4965 & 5138 & 5179 \\
\hline & & Mid & 4404 & 4230 & 4242 & 4544 & 4868 & 4109 \\
\hline & & Deep & 3953 & 3714 & 3731 & 4150 & 4612 & 3210 \\
\hline \multirow[t]{6}{*}{ Beijing } & SCDD* & Light & 343 & 391 & 402 & 347 & 282 & 275 \\
\hline & & Mid & 516 & 629 & 658 & 524 & 382 & 759 \\
\hline & & Deep & 720 & 933 & 987 & 736 & 489 & 1473 \\
\hline & SHDD* & Light & 2422 & 2321 & 2297 & 2413 & 2560 & 2578 \\
\hline & & Mid & 2084 & 1898 & 1855 & 2069 & 2340 & 1994 \\
\hline & & Deep & 1769 & 1519 & 1461 & 1748 & 2133 & 1030 \\
\hline \multirow[t]{6}{*}{ Chongqing } & SCDD* & Light & 499 & 594 & 648 & 590 & 492 & 478 \\
\hline & & Mid & 666 & 886 & 1014 & 877 & 650 & 1194 \\
\hline & & Deep & 851 & 1228 & 1451 & 1212 & 825 & 2171 \\
\hline & SHDD* & Light & 905 & 796 & 740 & 800 & 914 & 931 \\
\hline & & Mid & 722 & 529 & 437 & 536 & 738 & 328 \\
\hline & & Deep & 556 & 309 & 200 & 317 & 579 & 20 \\
\hline \multirow[t]{6}{*}{ Kunming } & SCDD* & Light & 0 & 1 & 5 & 2 & 0 & 0 \\
\hline & & Mid & 2 & 44 & 119 & 65 & 8 & 226 \\
\hline & & Deep & 19 & 202 & 426 & 280 & 52 & 1106 \\
\hline & SHDD* & Light & 1031 & 893 & 816 & 862 & 985 & 1027 \\
\hline & & Mid & 862 & 632 & 507 & 581 & 783 & 393 \\
\hline & & Deep & 714 & 412 & 261 & 352 & 610 & 64 \\
\hline \multirow[t]{6}{*}{ Guangzhou } & SCDD* & Light & 747 & 896 & 1019 & 976 & 854 & 764 \\
\hline & & Mid & 912 & 1248 & 1530 & 1433 & 1151 & 1770 \\
\hline & & Deep & 1093 & 1636 & 2098 & 1937 & 1478 & 3033 \\
\hline & SHDD* & Light & 309 & 243 & 198 & 212 & 261 & 301 \\
\hline & & Mid & 236 & 131 & 74 & 91 & 157 & 42 \\
\hline & & Deep & 174 & 58 & 17 & 28 & 82 & 0 \\
\hline
\end{tabular}

Note: S, south; SE, south-east; SW, south-west; E, east; W, west; NE, north-east; NW, north-west; N, north; H, horizontal.

method were not significantly different from those calculated by the DeST simulation $(P>0.05)$, indicating that the solar-air degree-day method results were sufficient for the engineering applications. Also, the results show that the solar-air degree-day method can estimate heating and cooling demand of poultry buildings for different climates: severe cold (Harbin), cold (Beijing), hot summer and cold winter (Chongqing), temperate (Kunming) and hot summer and warm winter (Guangzhou).

In the DeST simulation, the structural characteristics of the poultry buildings are considered constant, in other words, the assumed heat transfer coefficient of external envelopes is constant. The color of the poultry buildings outer surface may change after long-term use, experiments have not been conducted to analyze the influence of this factor due to the long experimental period, limited resources and labor, and Nawalany et al. ${ }^{[24]}$ and Shields et al. $^{[25]}$ reported that poultry buildings have specific microclimates, which should take into account a number of factors. Building airtightness has a significant influence on heating and cooling energy consumption of poultry buildings, but the poultry buildings construction was considered as airtight in the DeST simulation. The sensible and latent heat emission depends on environmental conditions and the latent heat emission is positively correlated with the raise of the temperature, while sensible heat production decreases with a rise in temperature. However, the assumed total heat production is determined as a function of weight in DeST simulation. Thus, further research is necessary to improve the accuracy, and 

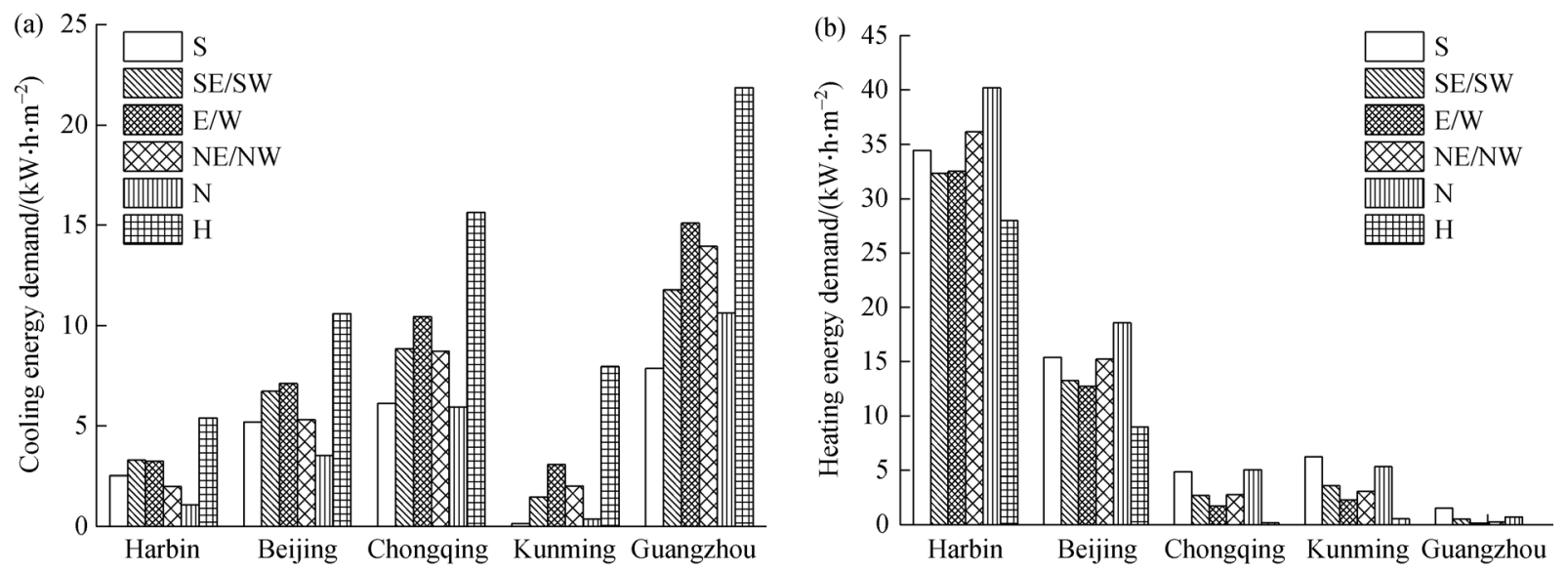

Fig. 4 Cooling (a) and heating (b) energy demand for six wall orientations of laying houses in five cities in different climate zones of China. S, south; SE, south-east; SW, south-west; E, east; W, west; NE, north-east; NW, north-west; N, north; H, horizontal.
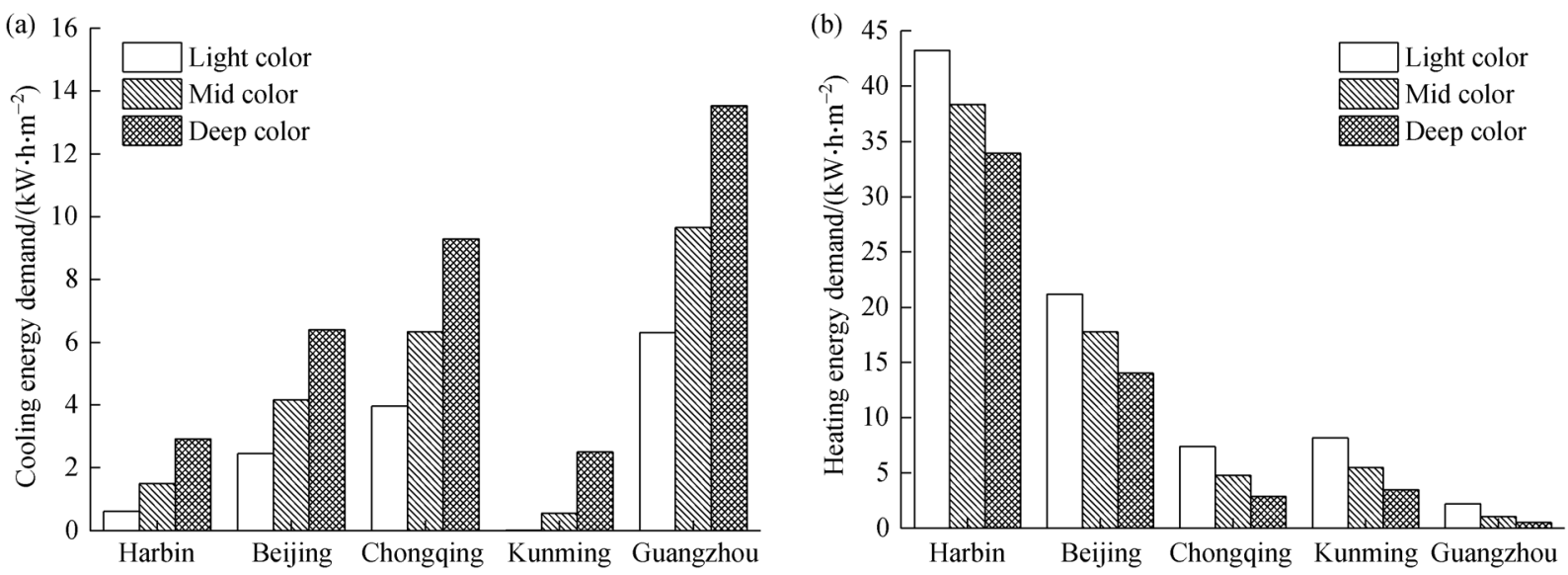

Fig. 5 Cooling (a) and heating (b) energy demand for laying houses with three surface color materials in five cities in different climate zones of China.

verification is needed due to the different structure and materials used in poultry buildings.

The solar-air degree-day concept assumes that the heat transfer through the wall is equal to the product of the wall conductance and the difference between the solar and inside air temperature. Erbs et al. ${ }^{[26]}$ reported that on an instantaneous basis this assumption will not always be satisfied due to energy storage within the wall, but degreedays provide reasonable estimates of heating and cooling loads when the solar temperature is always either less than or greater than the inside air temperature or when thermal storage within the walls and interior is small relative to the size of the load. Additional relationships are required to use the degree-day method, introducing other sources of uncertainty, but the non-solar curve indicates the accuracy of the degree-day method. A more systematic error which shows up in all locations at low base temperature values is the overprediction of solar degree-days, but the differences are small in magnitude ${ }^{[26]}$. Mattia et al. ${ }^{[8]}$ reported that a comparison between estimates of heating and cooling demand from the modified degree-day method and those from simulators (TRNSYS and Energy Plus) for three Italian cities with different climates (cold in Milan, moderate in Rome, and warm in Palermo), and the modified degree-day method used to estimate heating and cooling demand for the three cities because the heating and cooling demand showed no significant difference. As a result, the accuracy of estimating the cooling and heating energy demand was improved by the solar-air degree-day method, and results reported herein for the selected cities may be conveniently used to obtain reasonable estimates of solar-air degree-days for other cities within the different climate zones.

\subsection{Effect of solar-air temperature and base temperature}

The solar-air temperature and base temperature are basic values used for calculating the heating and cooling degreedays for buildings. The temperature difference between the solar-air temperature and the outside air temperature is 
equivalent to the effect of solar radiation, which is affected by solar radiation absorptance and daily average solar total radiation. The current study revealed that the wall orientation and surfaces color affect the temperature difference. The deeper the surface color, the higher the temperature difference. The reason for this is that the envelope orientation with various surface colors directly affects the solar radiation absorbed by the outside surfaces in buildings. Yu et al. ${ }^{[12]}$ determined solar-air degree-days to estimate energy consumption owing to space heating and cooling caused by the opaque envelope of residential buildings in the hot summer and cold winter zone of China, and also reported that the envelope orientation with various colored surfaces affected the solar-air degree-days. The base temperature represents the optimal internal production temperature in animal houses as reported by Lorusso and Maraziti ${ }^{[23]}$. The optimal internal production temperature of $18-24^{\circ} \mathrm{C}$ for laying hens (at $127-432 \mathrm{~d}$ ), and the base temperature is $24^{\circ} \mathrm{C}$ for cooling and $18^{\circ} \mathrm{C}$ for heating in this study. This work only considered laying hens $127-$ $432 \mathrm{~d}$ old, and chick/pullet buildings should also be analyzed by solar-air degrees to estimate required energy consumption. It is clear that increasing base temperature for various cities, decreased the solar-air cooling degreedays considerably and linearly, and the solar-air heating degree-days increased. Solar-air heating and cooling degree-days of different cities varied significantly for the same base temperatures, according to the climate zone. Identical trends and similar conclusions were obtained by Dombayc1 ${ }^{[27]}$ under different climate conditions in Turkey.

\subsection{Suggestions for reducing energy consumption}

Degree-day is a simple and efficient method for calculating the energy requirements of buildings. With the increase in solar-air degree-day value, the cooling and heating energy consumption increases linearly. Mattia et al. ${ }^{[8]}$ proposed a modified degree-day approach to simulate heating/cooling energy consumption in buildings and selected three illustrative cases with different climate conditions (Athens, warm climate; Florence, moderate climate; London, cold climate) to analyze given their common profile of the energy demand for heating and cooling. The solar-air degree-day method was proposed and developed to estimate cooling and heating energy consumption in poultry buildings, and to accurately calculate heating and cooling energy requirements in different climate zones.

In 2001, Büyükalaca et al. ${ }^{[28]}$ reported that thermal characteristics of the building and preferences of the occupants should be changed to reduce the base temperature, if possible. Additionally, thermal insulation should be applied to the buildings and air leakages should be minimized to obtain low base temperatures. Therefore, to enhance cooling energy savings in poultry buildings, the thermostat settings should be set to the higher limit of the optimum internal production temperature of poultry in summer and to the lower limit of the optimum internal production temperature of poultry in winter. It should be noted that horizontal orientations had great effect on cooling energy consumption but relatively less effect on heating energy consumption and with the increase of solarair degree-day value, the cooling and heating energy consumption increases linearly. These phenomena are attributed to the overall effect of solar radiation on equivalent temperature differences for different orientations with three surface colors in cooling and heating seasons and are reflected in the solar-air degree-day values $^{[14]}$. Thus, the effect of orientation and surface color on the reduction of thermal energy consumption needs to be considered. Especially for poultry buildings in Guangzhou and Harbin, the external walls should have different surface colors for different orientations, which can contribute to reducing the variability of energy demand and orientation and surface color were found to have a great effect on the energy consumption in Guangzhou and Harbin. Furthermore, applying light colored surface to poultry buildings is highly beneficial for reducing cooling energy consumption in Guangzhou and Chongqing, while deep colored surface should be applied to increase the use of solar energy to reduce heating energy consumption in Harbin. The reason for this is that solar radiation has significant influence on solar-air degree-day with different surface colors in Guangzhou, Chongqing and Harbin.

\section{Conclusions}

A solar-air degree-day method was developed and is proposed to simulate cooling and heating energy consumption in poultry buildings. The method considers the lower and higher limits of the optimum internal production temperature of poultry and the effects of solar radiation on wall orientation and surface color. The cities of Harbin, Beijing, Chongqing, Kunming, and Guangzhou were selected for study sites, to determine the solar-air degreedays, as they represent five climate zones in China, and results from these locations could be used for studies in other cities in each region. The heating and cooling energy demand for different climates using the solar-air degreeday method results were not significantly difference from those of the DeST simulation $(P>0.05)$. Therefore, the results obtained by the solar-air degree-day method are reliable and can be readily used in engineering applications under different climates. The accuracy of estimating the cooling and heating energy demand is improved by the solar-air degree-day method. An increase in base temperature reduced solar-air cooling degree-days linearly and significantly. Conversely, solar-air heating degree-days increased almost linearly. For energy savings in poultry buildings, thermostat settings should be controlled to the higher end of the optimum internal production temperature in summer and to the lower end of the optimum internal 
production temperature in winter. Applying light colors to external surfaces of poultry buildings is highly beneficial to reduce cooling energy consumption in Guangzhou and Chongqing, while deep colored surface should be used to increase the utilization of solar energy to reduce heating energy consumption in Harbin.

Acknowledgements This work was funded by the National Key R\&D Program of China (2018YFD0500700) and the China Agricultural Research System (CARS-40).

Compliance with ethics guidelines Yang Wang and Baoming Li declare that they have no conflicts of interest or financial conflicts to disclose.

The article does not contain any studies with human or animal subjects performed by any of the authors.

\section{References}

1. Zhao Y, Xin H, Shepherd T A, Hayes M D, Stinn J P. Modelling ventilation rate, balance temperature and supplemental heat need in alternative vs. conventional laying-hen housing systems. Biosystems Engineering, 2013, 115(3): 311-323

2. Wan K K W, Li D H W, Liu D, Lam J C. Future trends of building heating and cooling loads and energy consumption in different climates. Building and Environment, 2011, 46(1): 223-234

3. Wang Y, Zheng W C, Shi H P, Li B M. Optimising the design of confined laying hen house insulation requirements in cold climates without using supplementary heat. Biosystems Engineering, 2018, 174: 282-294

4. Oktay Z, Coskun C, Dincer I. A new approach for predicting cooling degree-hours and energy requirements in buildings. Energy, 2011, 36(8): 4855-4863

5. Marta B G, María D B. Environmental and cost performance of building's envelope insulation materials to reduce energy demand: thickness optimisation. Energy and Building, 2017, 150: 527-545

6. Isaac M, Vuuren D P V. Modeling global residential sector energy demand for heating and air conditioning in the context of climate change. Energy Policy, 2009, 37(2): 507-521

7. Bhatnagar M, Mathur J, Garg V. Determining base temperature for heating and cooling degree-days for India. Journal of Building Engineering, 2018, 18: 270-280

8. Mattia D R, Vincenzo B, Federico S, Luca A T. Heating and cooling building energy demands evaluation: a simplified model and a modified degree days approach. Applied Energy, 2014, 128: 217229

9. Yang L, Lam J C, Tsang C. Energy performance of building envelopes in different climate zones in China. Applied Energy, 2008, 85(9): 800-817

10. Crawley D, Hand J, Kummert M, Griffith B T. Contrasting the capabilities of building energy performance simulation programs. Building and Environment, 2008, 43(4): 661-673

11. Zoltán V, Ákos L, Ferenc K. Prediction of energy demand for heating of residential buildings using variable degree day. Energy, 2014, 76: 780-787

12. Yu J, Tian L, Yang C, Yang C, Xu X, Wang J. Optimum insulation thickness of residential roof with respect to solar-air degree-hours in hot summer and cold winter zone of china. Energy and Building, 2011, 43(9): 2304-2313

13. Ministry of Construction of the People's Republic of China. Code for Design of Civil Buildings (GB 50352-2005). Beijing: China Architecture and Building Press, 2012

14. Yu J, Yang C, Tian L, Liao D. A study on optimum insulation thicknesses of external walls in hot summer and cold winter zone of China. Applied Energy, 2009, 86(11): 2520-2529

15. Ucar A, Balo F. Effect of fuel type on the optimum thickness of selected insulation materials for the four different climatic regions of Turkey. Applied Energy, 2009, 86(5): 730-736

16. Ministry of Construction of the People's Republic of China. Design Code for Heating Ventilation and Air Conditioning of Civil Buildings (GB 50736-2012). Beijing: China Architecture and Building Press, 2012

17. Kocaman B, Esenbuga N, Yildiz A, Lacin E. Effect of environmental conditions in poultry houses on the performance of laying hens. International Journal of Poultry Science, 2006, 5(1): 26-30

18. Olgun M M, Çelik M Y, Polat H E. Determining of heat balance design criteria for laying hen houses under continental climate conditions. Building and Environment, 2007, 42(1): 355-365

19. Kreider J F. Handbook of Heating, Ventilation, and Air Conditioning. Boca Raton, USA: CRC Press (Taylor \& Francis Group), 2001

20. Yan D, Xia J, Tang W, Song F, Zhang X, Jiang Y. DeST-an integrated building simulation toolkit part I: fundamentals. Building Simulation, 2008, 1(2): 95-110

21. Zhu D D, Yan D, Li Z. Modelling and applications of annual energyusing simulation module of separated heat pipe heat exchanger. Energy and Building, 2013, 57: 26-33

22. Peng C, Wang L, Zhang X. DeST-based dynamic simulation and energy efficiency retrofit analysis of commercial buildings in the hot summer/cold winter zone of China: a case in Nanjing. Energy and Building, 2014, 78: 123-131

23. Lorusso A, Maraziti F. Heating system projects using the degreedays method in livestock buildings. Journal of Agricultural Engineering Research, 1998, 71(3): 285-290

24. Nawalany G, Bieda W, Radoń J. Effect of floor heating and cooling of bedding on thermal conditions in the living area of broiler chickens. Archiv für Geflügelkunde, 2010, 74: 98-101

25. Shields S J, Garner J P, Mench J A. Effect of sand and woodshavings bedding on the behavior of broiler chickens. Poultry Science, 2005, 84(12): 1816-1824

26. Erbs D, Klein S, Beckman W. Sol-air heating and cooling degreedays. Solar Energy, 1984, 33(6): 605-612

27. Dombaycı Ö A. Degree-days maps of Turkey for various base temperatures. Energy, 2009, 34(11): 1807-1812

28. Büyükalaca $\mathrm{O}$, Bulut H, Yilmaz T. Analysis of variable-base heating and cooling degree-days for Turkey. Applied Energy, 2001, 69(4): 269-283 